\title{
Body weight perceptions and obesity amongst university employed South African women
}

\author{
P. J. Gradidge (1) ${ }^{\mathrm{a}}$, Precious Golele ${ }^{\mathrm{a}}$, and Emmanuel Cohen ${ }^{\mathrm{b}, c}$ \\ "Centre for Exercise Science and Sports Medicine, Faculty of Health Sciences, University of the Witwatersrand, \\ Johannesburg, South Africa; ${ }^{b} \mathrm{MRC}$ Wits Developmental Pathways for Health Research Unit, Department of \\ Paediatrics, Faculty of Health Sciences, University of the Witwatersrand, Johannesburg, South Africa; 'UMR \\ CNRS-MNHN 7206 "Eco-anthropologie", Musée de l'Homme, Paris, France
}

\begin{abstract}
This study aimed to rigorously assess body weight perceptions according to several body image dimensions in rural, employed African women. One hundred and thirty-two employed black African women were recruited at a rural South African university. Participants were asked to choose their 'ideal' and 'feel' perceived body size from nine standardized body image silhouettes, varying according to body size. Three body image dimensions of interest were measured, (1) 'feel' minus 'ideal' index (FID), (2) perceived minus the actual weight status (PAD) index and (3) valorization of stoutness index (participants that chose silhouettes corresponding to overweight/obesity). Using the FID dimension, older obese women had significantly higher desire for leanness, with small effects, compared with lean and younger obese women $(p=.001)$. Those women who correctly perceived body weight $(P A D=0)$, were mostly obese and older $(p<.0001)$, with moderate effects, than non-obese women. Social valorization of stoutness was observed in $58.3 \%$ of the sample, but was higher in older obese women, with small effects, compared with lean women $(p=.0001)$. This study has shown that the majority of the study population demonstrated a social valorization of stoutness, despite a desire to be thinner and the ability to adequately perceive their own body weight in accordance with BMI.
\end{abstract}

\section{ARTICLE HISTORY}

Received 1 March 2019

Revised 17 March 2020

Accepted 2 April 2020

\section{KEYWORDS}

Body weight perceptions; obesity; rural; South Africa: women

\section{Introduction}

Obesity is a disease or morphology that exposes vulnerable population to cardiometabolic diseases as well as a pandemic that does not seem to be dissipating. Body mass index (BMI) is used widely in epidemiological studies to estimate the presence of obesity. Recent evidence confirms the varying influence of obesity in different geographical locations, with a trend toward plateauing in affluent countries and a high likelihood of continued upward trend in emerging nations (NCD Risk Factor Collaboration (NCD-RisC) - Africa Working Group 2017; NCD Risk Factor Collaboration (NCD-RisC) 2016). These data also show that poor women living in rural regions in sub-Saharan African (SSA) countries are vulnerable, such as observed in Malawi recently, because of the urbanization process (e.g. development of processed energy-dense foods) also includes rural areas (Price et al. 2018). This is particularly the case in South Africa, a middleincome country showing the highest rural and urban prevalence of obesity in the SSA region, 
especially in women. (NCD Risk Factor Collaboration (NCD-RisC) - Africa Working Group 2017; van Zyl et al. 2012).

Evidence has demonstrated that body weight perception has a role in the development of obesity risk in African populations, particularly among African women (Cohen et al. 2019a; Gradidge et al. 2015). Body weight perception can be measured as a proxy indicator of body weight dissatisfaction by the discrepancy between one's perceived versus ideal body size using body image scales (Williamson et al. 1993). In general, it is an exercise in considering the self-perceived attitude toward the body weight and size, in order to develop tailored interventions aiming to prevent obesity complications associated with a distorted body image perception (Holdsworth et al. 2004; Puoane et al. 2005). Earlier studies in South Africa using body image scales to determine body weight perception showed that black African females, either normal weight, overweight or obese, wanted to gain weight or underestimated their body weight, which could increase the risk of obesity (Puoane et al. 2013). These studies suggested that poor health outcomes such as obesity could be a consequence of negative body image perception (Mciza et al. 2005; Sonneville et al. 2012). The misperception of body weight could also result in behaviors associated with increased obesity risk such as physical inactivity, tobacco smoking, and poor dietary behavior (Mchiza et al. 2015).

Traditionally a larger body weight has been favored more by black South African women, perceived as a symbol of peaceful life, health, wealth, and respect (Chesler 1961; Mvo, Dick, and Steyn 1999; Puoane et al. 2005), whereas being lean is considered to be weak, and linked with scarcity and chronic infectious diseases (Matoti-Mvalo and Puoane 2011). This concept is known as the social valorization of stoutness (at least overweight), and appears to be associated with a higher risk of obesity amongst African populations (Cohen et al. 2013, 2019b). Indeed, the misperception of unhealthy body weight can influence the risk of overweight and obesity, particularly in obesogenic, urbanized environments where the accessibility to high-calorie food and the development of advancing transport systems exist (Leontiadis and Howden 2010).

More recent studies have shown that the body image perception concepts are shifting in both adolescent and adult female populations through the influence of Western acculturation in urban South Africa (Gitau et al. 2014b; Gradidge et al. 2015), with an emerging expansion of this phenomenon into rural areas (Prioreschi et al. 2017). Self-perception of body image seems to shifting toward favoring thinner body size among South African adolescent females (Gitau et al. 2014a), while in adult South African women, and particularly among obese women, body image constructs are more complex (Cohen et al. 2019a), as observed in other African countries (Cohen et al. 2019b). A longitudinal study has observed that self-perception of South African urban women could fall into a range of three possible body image constructs; those who are content with body size, those who are dissatisfied with body size, and those who desire larger body sizes (Gradidge et al. 2015). Importantly, these studies suggest the existence of complex contemporary body weight norms, one where the idea of acculturation toward Western body ideals in the midst of continued acceptance of large body size in African populations.

Data on the association between different body image constructs and the nutritional health of African women are limited. Most studies conducted in South Africa used one or two body image dimensions (i.e. body weight dissatisfaction or/and body weight underestimation) to assess potential body image constructs associated with higher BMI, limiting 
the understanding of the association between body weight perceptions and obesity in the African context. Evidence on these constructs in employed African women can help augment efforts to address obesity in African communities as most homes are led by women, requiring a multidimensional approach (Affenito et al. 2012). For example, interventions can target behavior modification in employed African women, who may, in turn, become enablers of behaviors that contribute weight reduction in their own family and community members (Affenito et al. 2012), especially in rural areas where the traditional valorization of stoutness remains persistent (Cohen et al. 2017; Prioreschi et al. 2017). Therefore, the overall aim of this study was to determine constructs of body weight perception between obese and non-obese black South African women working at a rural university, using three body image dimensions/indices: body weight dissatisfaction, body weight self-estimation, and social valorization of stoutness, in order to determine the association of these measures, coupled with several sociodemographic variables (occupation type, monthly income, work experience, and ownership of household assets), with BMI. This in-depth investigation on body image can better characterize the role of body weight perceptions as a risk factor for overweight and obesity among black women in the context of urbanization and modernization of South Africa, and support workplace interventions aiming to prevent obesity in this population.

\section{Methods}

\section{Study population}

This cross-sectional study was conducted at the University of Venda, a rural-based academic institution based in the Limpopo province of South Africa. The staff members of the university were informed about the study via e-mail and with the assistance of the human resources department and were recruited at a meeting held to inform the staff about the procedures of the study. The eligibility criteria included aged 18-65 years, black South African, working at the University of Venda (full- or part-time), female, no current pregnancy, nonsmoker. Three hundred and ninety-four women at the university were potentially eligible; 132 of these women agreed to participate and provided written consent. The required sample size of 118 is based on data from previous research on body size dissatisfaction in adult African women (Gradidge et al. 2015), with a power of $80 \%$ at 0.05 . The actual sample size of 132 is above the target sample number. Participants were informed that participation in the study was voluntary, and besides ensuring confidentiality, the researchers assured participants that usual academic activities would not be hampered. The ethics committee of the University of the Witwatersrand granted permission for the study (ethics certificate number: M160518), and the management of the University of Venda granted access to engage with the staff members.

\section{Anthropometry}

Standing height (PHR, USA) and weight (Seca, Hamburg, Germany) were measured to the closest $0.1 \mathrm{~cm}$ and $0.01 \mathrm{~kg}$, respectively, using the protocol of the American College of Sports Medicine. Waist circumference was measured using a measuring tape at the narrowest truncal region, with participants standing upright, arms relaxed, and feet together (American College of 
Sports Medicine 2018). Hip circumference was measured in a similar manner around the widest gluteal region. BMI in $\mathrm{kg} / \mathrm{m}^{2}$ and waist-to-height ratios were calculated.

\section{Physical activity and socioeconomic status}

Self-reported physical activity measures were determined using a validated instrument to determine total moderate-vigorous physical activity (MVPA) and sitting time (Bull, Maslin, and Armstrong 2009). The decision to not collect education status was based on the evidence that access to household assets and contribution to household income are better indicators of the socioeconomic status in African women at risk of obesity (Case and Menendez 2009; Griffiths et al. 2008). A questionnaire elicited ownership of eleven assets ranked in order of value from the lowest to the highest value. These assets included radio (coded as ' 1 '), computer (coded as ' 2 '), refrigerator (coded as ' 3 '), washing machine (coded as ' 4 '), television (TV) (coded as ' 5 '), telephone (coded as ' 6 '), mobile phone (coded as ' 7 '), monthly internet subscription (coded as ' 8 '), electricity (coded as ' 9 '), satellite TV (coded as ' $10^{\prime}$ ), and motor vehicle (coded as ' $11^{\prime}$ ). An SES score was calculated by summing the scores from the respective items, with possible scores ranging ' 0 ' to ' 66 '. The SES scores were then stratified into low SES (SES score: 0 to 38), moderate SES (SES score: 39 to 51 ), and high SES (SES score: $\geq 52$ ). Other measures of SES were considered including marital status (coded as single or $\left({ }^{(} 0^{\prime}\right)$ or living together $\left({ }^{\prime}{ }^{\prime}{ }^{\prime}\right)$ ), monthly income, and occupation type (academic, coded as ' 1 ' or non-academic, coded as ' 0 ').

\section{Body weight perception}

The use of body image scales (silhouettes or pictorial body image models) to assess multiple dimensions on body weight perceptions in black South African women has been validated and accepted for use in epidemiologic studies (Mchiza, Goedecke, and Lambert 2011; Mciza et al. 2005). On the Figure rating Scale (FRS) developed and validated by Stunkard et al. (1983), participants were asked to select body silhouettes that best matched their current (or 'feel') and ideal body weight perceptions. The silhouettes were coded from 1 to 9, according to body size. Codes 1 and 2 represented underweight category, codes 3 and 4 represented normal weight category, codes 5 and 6 represented the overweight category, and codes 7-9 represented the obese category. To assess the body weight dissatisfaction of participants, the 'feel' minus the 'ideal' score (FID) was calculated, with positive scores denoting a desire to be leaner, zero showing contentment, and negative scores indicating a desire to be fatter (Gradidge et al. 2015). For example, if a participant chose a 'feel' silhouette coded as 5 and an ideal silhouette coded as 4 , then the FID score would be -1 . Possible scores would, therefore, depend on the silhouettes, chosen, respectively.

The perceived (using the recoded 'feel' body weight silhouettes) minus the actual weight status (using BMI categories, underweight $=1$, normal weight $=2$, overweight $=3$, and obese $=4$ ) discrepancy index or perceived minus the actual weight status (PAD) was determined to assess the body weight self-estimation of participants (Gradidge et al. 2015). The 'feel' silhouettes were recoded according to the corresponding BMI category, i.e. codes $1-2$ were recoded as ' 1 ', codes 3-4 were recoded as ' 2 ', codes 5-6 were recoded as ' 3 ' and codes 7-9 were recoded as ' 4 '. The scores for PAD represent a measure of accuracy for 
perceiving actual weight, with positive scores representing overestimation, negative scores underestimation, and zero correct perception of body weight.

In addition, a dummy variable for the social valorization of the stoutness of participants (a desire to be at least overweight) (Cohen et al. 2013) was created using body image silhouettes with a score $\geq 5$ to represent preference for the overweight and obese 'ideal' body image silhouettes (Matoti-Mvalo and Puoane 2011).

\section{Statistical analysis}

The Statistica software package was used for all statistical analyses (version 13.2, TIBCO Software Inc, Palo Alto, CA, USA). Normally distributed continuous data were presented as mean $\pm S D$, while skewed data are presented as median (interquartile range [IQR]). Independent t-tests were used to determine the differences between obese and non-obese participants. Age tertiles were created for analysis, with the lowest tertile $(n=37)$ aged $<35$ years, second tertile $(n=48)$ aged $36-43$ years and oldest tertile $(n=47)$ aged $\geq 44$ years. A new cluster variable was created using age tertiles to compare, using Pearson Chi-square, body image constructs between participants that were non-obese $(n=60)$ and those women obese in the lowest age tertile $(n=7)$, obese in the second age tertile $(n=29)$, and obese women in the oldest age tertile $(n=36)$. Effect sizes were reported in the text and considered as small (values $\leq 0.49$ ), moderate (values 0.50 to 0.79 ) and large (values $\geq 0.80$ ). Bivariate analysis was conducted between BMI and age, SES, FID $>0$, $\mathrm{FID}<0, \mathrm{PAD}>0, \mathrm{PAD}<0$, and social valorization of stoutness.

A multiple linear regression analysis was conducted to determine whether the social valorization of stoutness was associated with BMI. The model included scientifically plausible independent variables that had a $p<.20$ from the bivariate analysis: SES, sitting time, and social valorization of stoutness as independent variables. Age was included as a confounding variable in the regression model. The inclusion of this confounder was based on previous studies, which demonstrated that BMI increases with age in African women. (Gradidge et al. 2014, 2015). The strength and direction of the association is displayed through standardized beta $(\beta)$ values. The Variance Inflation Factor (VIF) was used to check collinearity between the exposure variables, and no collinearity was displayed (VIF range: 1.03-1.79). The model fit was assessed using the R-squared, overall F-test, and sum of squares.

\section{Results}

\section{Participant characteristics}

All study participants were black South African with a mean age of the participants was $40 \pm 10.1$ years; their mean BMI was $31.5 \pm 6.82 \mathrm{~kg} \cdot \mathrm{m}^{-2}$, and mean waist circumference was $93.8 \pm 16.5 \mathrm{~cm}$ (Table 1). Participants who were obese (54.5\%) were older, received similar monthly incomes and had longer work experience than those who were non-obese, however, this was due to the positive correlation of age with work experience $(\mathrm{r}=0.67, p<.0001)$ as the effect was small $(<0.5)$. The study population was mostly in non-academic roles, with no statistically significant differences in household SES observed between obese and non-obese women. Sitting time was statistically higher in the obese women $(p=.03)$; however, the effect 
Table 1. Participant characteristics by obesity status ${ }^{\mathrm{a}}$.

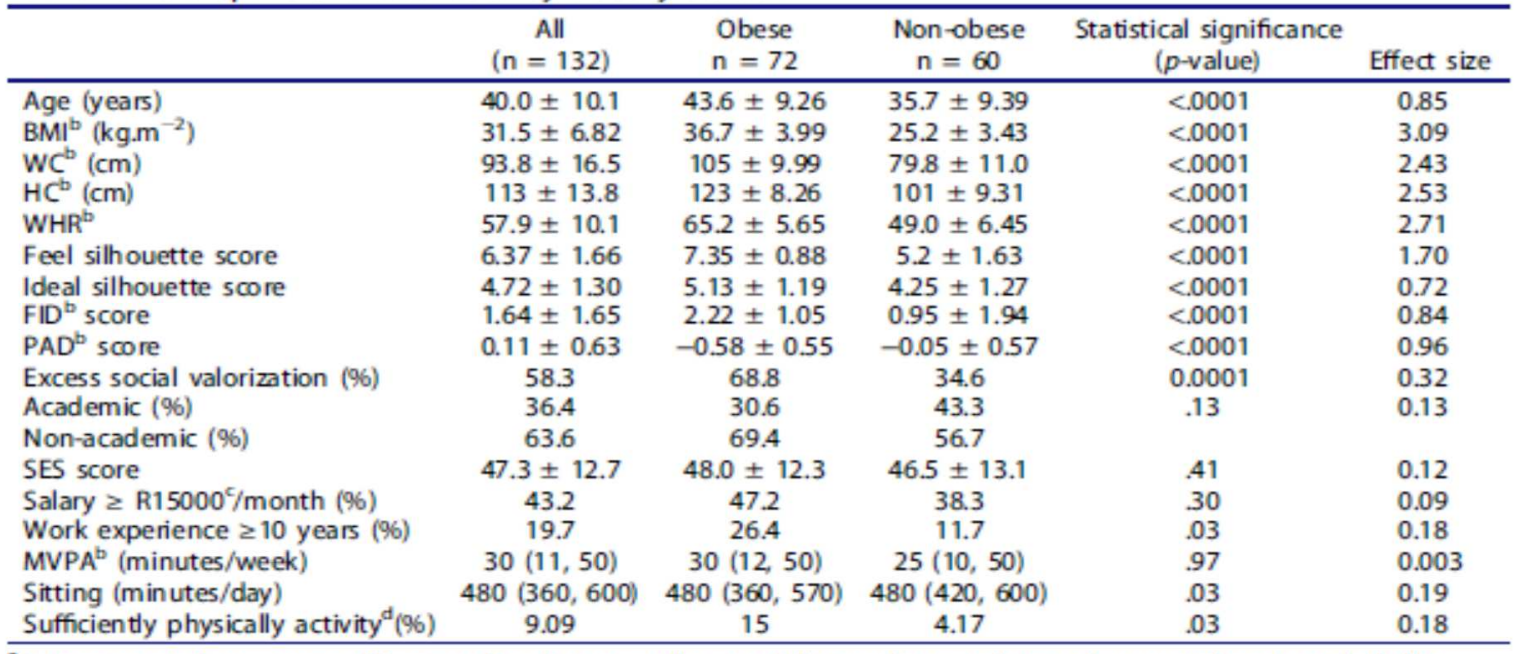

Data presented as mean \pm SD or median (interquartile range) for continuous data and percent for categorical data.

${ }^{\mathrm{b}} \mathrm{BMI}=$ body mass index; $\mathrm{WC}=$ waist circumference; $\mathrm{HC}=$ hip circumference; $\mathrm{WH} \mathrm{H} \mathrm{R}=$ waist-to-height ratio; $\mathrm{FID}=$ feel minus ideal score; PAD = perceived minus actual weight status; SES = socioeconomic status; MVPA = moderate-tovigorous physical activity.

'Equivalent to approximately $\$ 1020 /$ month.

${ }^{\mathrm{d} S u f f i c i e n t}$ physical activity $=150$ minutes/week, moderate-to-vigorous physical activity.

was small $(<0.5)$. Likewise, statistically more non-obese women obtained a sufficient amount of physical activity than obese women $(p=.03)$, but this effect was small. Regarding the preliminary trends on body weight perceptions assessed by the FRS, the participants who were non-obese chose silhouettes that were significantly lower in score compared with the women who were obese. Obese women did have statistically higher FID scores than non-obese women, with a large effect size ( $>0.80)$, indicating a desire for leanness.

\section{Body weight dissatisfaction}

In an ANOVA analysis, most of the participants $(\mathrm{n}=109,82.6 \%)$ reported a desire to be leaner (FID scores $>0$ ) (Figure 1), with a small effect size of 0.41 . The remainder of the participants reported a desire to be fatter $(\mathrm{n}=14,10.6 \%)$ while $6.8 \%(\mathrm{n}=9)$ of the participants were content with their body weight (FID score $=0$ ). Moreover, $69 \%$ of the participants who showed a desire to lower their body weight were obese compared with $36.7 \%$ who were non-obese. In a bivariate analysis FID $<0$ was inversely associated with BMI $(\beta=-0.50, p<.0001)$, while FID $>0$ was positively correlated with BMI $(\beta=0.56, p<.0001)$. Age was significantly correlated with BMI $(\mathrm{r}=0.50, p<.0001)$. Moderate SES was inversely correlated with BMI $(\beta=-0.16, p=.06)$, while high SES was positively correlated with BMI $(\beta=0.16, p=.07)$.

\section{Body weight self-estimation}

The effect size for obesity on PAD scores was large ( $>0.80$ ), with the obese group showing statistically higher negative PAD scores than the non-obese group (Table 1). The majority of 
a

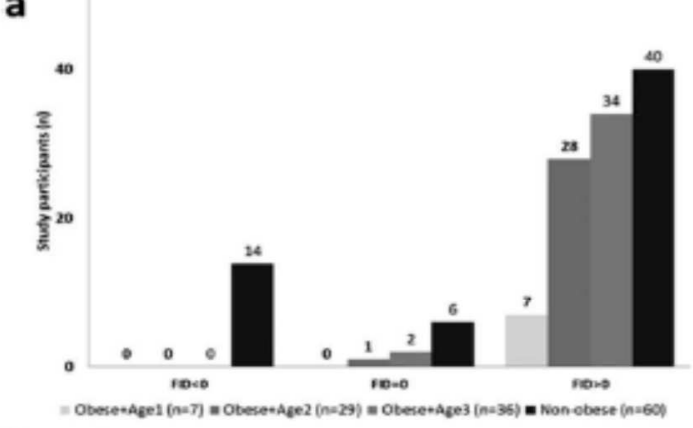

c

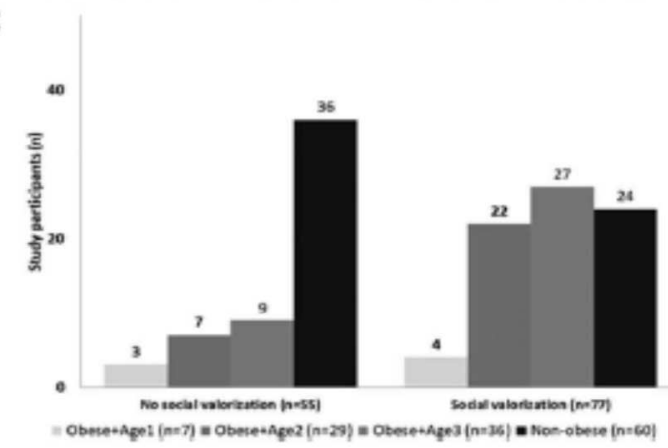

b

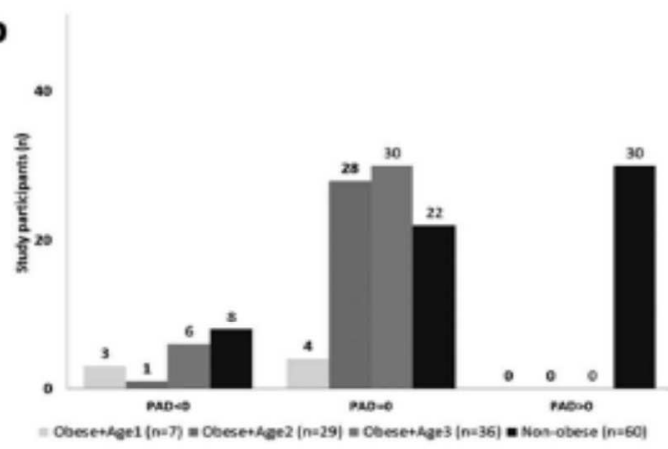

Figure 1. Comparison of body weight dissatisfaction (a) and body weight perceived-actual discrepancy (b) and social valorization of stoutness (c) in obese and non-obese African women.

PAD: perceived minus actual weight status; FID: feel minus ideal score; FID $<0$ indicates a desire to be fatter, FID $>0$ indicates a desire to be leaner and FID $=0$ indicates contentment with body size; $\mathrm{PAD}<0$ indicates underestimation of body weight, $\mathrm{PAD}<0$ indicates overestimation of body weight and $P A D=0$ indicates accurate perception of body weight.

the sample ( $\mathrm{n}=84,63.6 \%$ ) was able to correctly perceive their actual body weight according to their BMI (Figure 1), with a moderate effect size of 0.61 . In addition, most of these participants were obese $(n=62,73.8 \%)$ compared with $26.2 \%(n=22)$ that were lean.

\section{Social valorization of stoutness}

A majority of the sample (58.3\%) demonstrated a social valorization of stoutness. Social valorization of stoutness was significantly positively associated with BMI $(p<.001)$, accounting for $30 \%$ of the BMI variance in a multiple linear regression including age, sitting time, and SES as predictors of BMI (Table 2). In a simple linear regression, we also observed a non-significant trend for those in the lowest tertile of age (participants aged 23-34 years) to have lower social valorization of stoutness compared to the older participants $(\beta=-0.16, p=.07)$. BMI was negatively associated with $\mathrm{PAD}<0(\beta=-0.44$, $p<.0001$ ); however, PAD $>0$ was not associated with $\mathrm{BMI}$ in a simple linear regression analysis. The sociodemographic factors, physical activity, and sitting time were not associated with BMI. 
Table 2. Multiple linear regression of age, sitting time, SES, and body image with BMI.

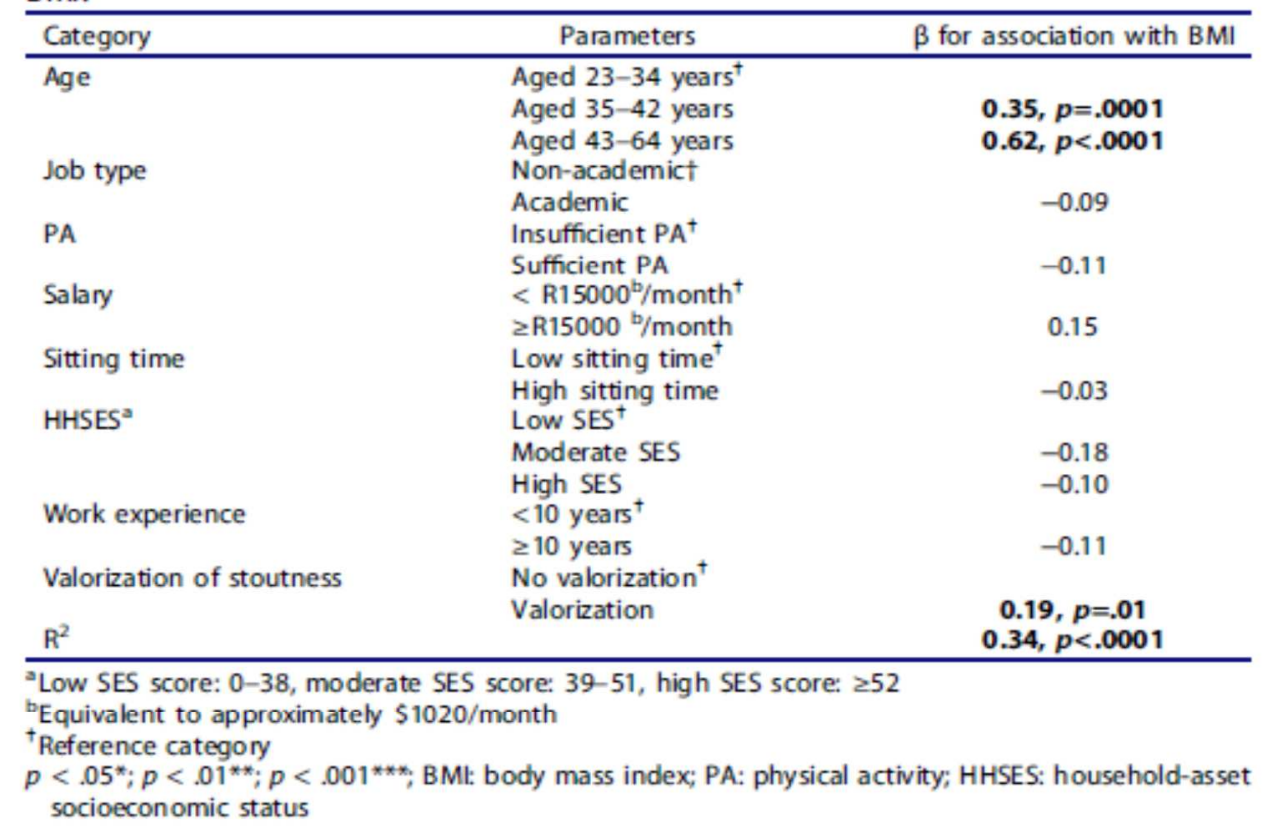

\section{Discussion}

The findings of this cross-sectional study show that most of the participants had a desire to be leaner (FID scores $>0$ ) and the majority of the sample was able to correctly perceive their actual body weight according to their BMI. In addition, most of these participants were older obese women who showed a social valorization for stoutness, with a small number of obese women underestimating their body weight. These findings confirm (1) previous African studies observing acculturation of traditional African body image constructs amidst western ideals of beauty, and confirm (2) that obese African women value overweight despite most obese showing a desire to lower body weight.

The desire to have a thinner body size among African women is an emerging theme in African literature, with recent data highlighting the acculturation taking place in various sub-Saharan African settings (Cohen et al. 2019b; Gradidge et al. 2015). The findings of the present study showed that this study population of mostly obese African women demonstrates two main body image constructs with the majority wanting to be thinner (FID scores $>0$ ), while others were content with existing body size (FID scores $=0$ ). This finding shows the complexity in body weight constructs, and suggests a broader shift away from traditional Afrocentric psycho-cultural processes valuing stoutness. Indeed, the literature in South Africa shows that adolescent African females are experiencing a shift in preference toward a thinner body size (Gitau et al. 2014a). This fundamental change in perception can affect body weight dissatisfaction as indicated by the high FID scores in this study, which can be associated with eating disorders (Prioreschi et al. 2017), especially in African women with BMI readings in the overweight/obese category (BMI $\geq 25 \mathrm{~kg} \cdot \mathrm{m}^{-2}$ ) further exacerbating health concerns (Cohen et al. 2019a; Gitau et al. 2014a). 
Literature suggests that those overweight or obese subjects with higher body dissatisfaction may also engage in weight management practices to lower body weight (Mchiza et al. 2015). These can include the physical activity programs to improve cardiovascular health, with recent data showing that the implementation of even small amounts of physical activity can protect against the onset of co-morbid diseases (Kraus et al. 2019). Given the high sitting time of the subjects in our study ( $\sim 8$ hours/day) with evidence of body dissatisfaction, urgent intervention in the workplace is required, particularly as the presence of obesity continues to grow in the wider South African context.

We observed that most of the sample of obese women demonstrating an ability to adequately perceive BMI, while a minority underestimated actual body weight status. This study finding is in contrast to existing evidence which shows that the majority of obese African women tend to underestimate actual body weight status size (Puoane et al. 2002; Puoane, Tsolekile, and Steyn 2010). However, only $12 \%$ of the obese subjects in the present study underestimated their body size, despite having an elevated mean BMI of $35.1 \pm 3.44 \mathrm{~kg} \cdot \mathrm{m}^{-2}$. Subjects who adequately perceived body weight tended to be obese and older compared with lean women, with our findings suggesting a smaller effect amongst women in the lower age tertile.

Black African women are particularly vulnerable to obesity-related noncommunicable disease in South Africa (Cois and Ehrlich 2014), and this exposure can be exacerbated by a desire for overweight or obesity. Indeed, our findings suggest that the present study population might be at risk of obesity and co-morbid diseases through the high proportion of participants with a social valorization of stoutness. Previous studies of African women in Cameroon and Senegal, two distinct geographical regions, have also observed that the social appreciation for stoutness is a determinant of overweight of obesity. Moreover, these studies showed a positive association between this social valorization of stoutness and age (Cohen et al. 2013, $2019 \mathrm{~b}$ ), suggesting also the coexistence of the two body image constructs between younger and older African women. Our study also demonstrated this trend, although non-significant, between younger age and lower social valorization of stoutness $(p=.07)$, but also shows that older obese women have a higher risk of this body image construct. This raises for older African women as this cohort may have a higher risk of obesity-related cardiometabolic disease (Tang et al. 2013).

The main strength of this study was that three dimensions of body image were used to rigorously describe and demonstrate the shift in body image toward thinness coexisting with a social valorization of stoutness as a determinant of obesity. These findings will help to inform South African public health programs to develop interventions in the rural community, through the workplace of the population, to better reduce the at-risk cultural norms favoring obesity in Black women. Future research should, therefore, concentrate on developing sustainable culture- and gender-specific programs to address obesity risk within an African context.

The study has some limitations worth considering. One limitation of this study was that a non-African group of women was not available for comparison of body weight perception. Other possible limitations included the potential for participant bias due to the poor participation rate, which may affect the accuracy and generalizability of the results; the potential for residual confounding; the potential for selection bias due to selecting 
employees from a single institution, which may have reduced the generalizability of findings; and the potential for reporting and social acceptability bias.

\section{Conclusions}

The findings of this cross-sectional study have shown that the presence of obesity is high among this study cohort of employed African women, with the obese group of women demonstrating a higher likelihood to desire thinness, despite the ability to correctly perceive actual body weight compared with lean women. These important findings are reflective of the on-going acculturation toward thinness amidst a growing prevalence of obesity, although a persistent social valorization of stoutness was also observed, associated with a higher risk of BMI. Future studies and interventions can build on these observations to define appropriate workplace strategies to address cultural factors favoring obesity amongst employed rural Black African women.

\section{Acknowledgments}

The authors thank the participants involved in this study. The South African Medical Research Council and the South African National Research Foundation support P. J. Gradidge.

\section{Author contributions}

Research concept and design: P. J. Gradidge; Data analysis and interpretation: P. J. Gradidge, Emmanuel Cohen; Manuscript draft: P. J. Gradidge, Statistical expertise: P. J. Gradidge; Acquisition of funding: P. J. Gradidge; Administrative: P. J. Gradidge; Supervision: P. J. Gradidge.

\section{Disclosure statement}

No potential conflict of interest was reported by the authors.

\section{ORCID}

P. J. Gradidge (ib) http://orcid.org/0000-0001-5225-1184

\section{References}

Affenito, S. G., D. L. Franko, R. H. Striegel-Moore, and D. Thompson. 2012. Behavioral determinants of obesity: Research findings and policy implications. Journal of Obesity 2012:150732-150732. doi: $10.1155 / 2012 / 150732$.

American College of Sports Medicine. 2018. ACSM's guidelines for exercise testing and prescription, ed. D. Riebe, 10th ed. Philadelphia, PA: Wolters Kluwer Health.

Bull, F. C., T. S. Maslin, and T. Armstrong. 2009. Global physical activity questionnaire (GPAQ): Nine country reliability and validity study. Journal of Physical Activity of Health 6:790-804. doi: 10.1123/jpah.6.6.790.

Case, A., and A. Menendez. 2009. Sex differences in obesity rates in poor countries: Evidence from South Africa. Economics and Human Biology 7 (3):271-82. doi:10.1016/j.ehb.2009.07.002.

Chesler, J. 1961. A study of attitudes and knowledge concerning obesity in an urban African community. South African Medical Journal 35:129-31. 
Cohen, E., N. Amougou, A. Ponty, J. Loinger-Beck, T. Nkuintchua, N. Monteillet, J. Y. Bernard, R. Saïd-Mohamed, M. Holdsworth, and P. Pasquet. 2017. Nutrition transition and biocultural determinants of obesity among cameroonian migrants in urban Cameroon and France. International Journal of Environmental Research and Public Health 14 (7):696. doi:10.3390/ ijerph 14070696.

Cohen, E., G. Boetsch, F. P. Palstra, and P. Pasquet. 2013. Social valorisation of stoutness as a determinant of obesity in the context of nutritional transition in Cameroon: The Bamiléké case. Social Science of Medicine 96:24-32. doi:10.1016/j.socscimed.2013.07.004.

Cohen, E., P. J. Gradidge, L. K. Micklesfield, and S. A. Norris. 2019a. Relationship between body mass index and body image disturbances among South African mothers and their daughters living in Soweto, Johannesburg. Family \& Community Health 42 (2):140-49. doi:10.1097/ fch.0000000000000220.

Cohen, E., P. J. Gradidge, A. Ndao, P. Duboz, E. Macia, L. Gueye, G. Boëtsch, P. Pasquet, M. Holdsworth, and N. Chapuis-Lucciani. 2019b. Biocultural determinants of overweight and obesity in the context of nutrition transition in Senegal: A holistic anthropological approach. Journal of Biosocial Science 51 (4):469-90. doi:10.1017/S0021932018000287.

Cois, A., and R. Ehrlich. 2014. Analysing the socioeconomic determinants of hypertension in South Africa: A structural equation modelling approach. BMC Public Health 14:414. doi:10.1186/14712458-14-414.

Gitau, T. M., L. K. Micklesfield, J. M. Pettifor, and S. A. Norris. 2014a. Ethnic differences in eating attitudes, body image and self-esteem among adolescent females living in urban South Africa. African Journal of Psychiatry 17:468-74. doi:10.4172/1994-8220.1000101.

Gitau, T. M., L. K. Micklesfield, J. M. Pettifor, and S. A. Norris. 2014b. Changes in eating attitudes, body esteem and weight control behaviours during adolescence in a South African cohort. PloS One 9 (10):e109709. doi:10.1371/journal.pone.0109709.

Gradidge, P. J., N. J. Crowther, E. D. Chirwa, S. A. Norris, and L. K. Micklesfield. 2014. Patterns, levels and correlates of self-reported physical activity in urban Soweto women. BMC Public Health 14:934. doi:10.1186/1471-2458-14-934.

Gradidge, P. J., S. A. Norris, L. K. Micklesfield, and N. J. Crowther. 2015. The role of lifestyle and psycho-social factors in predicting changes in body composition in black South African women. PloS One 10 (7):e013291. doi:10.1371/journal.pone.0132914.

Griffiths, P. L., E. K. Rousham, S. A. Norris, J. M. Pettifor, and N. Cameron. 2008. Socio-economic status and body composition outcomes in urban South African children. Archives of Disease in Childhood 93 (10):862-67. doi:10.1136/adc.2006.112649.

Holdsworth, M., A. Gartner, E. Landais, B. Maire, and F. Delpeuch. 2004. Perceptions of healthy and desirable body size in urban Senegalese women. International Journal of Obesity 28 (12): 1561-68. doi:10.1038/sj.ijo.0802739.

Kraus, W. E., K. E. Powell, W. L. Haskell, K. F. Janz, W. W. Campbell, J. M. Jakicic, R. P. Troiano, K. Sprow, A. Torres, K. L. Piercy, and For the 2018 Physical Activity Guidelines Advisory Committee. 2019. Physical activity, all-cause and cardiovascular mortality, and cardiovascular disease. Medicine and Science in Sports and Exercise. 51 (6):1270-81. doi:10.1249/ mss.0000000000001939.

Leontiadis, G. I. H., and C. W. Howden. 2010. Body size misperception: A novel determinant in the obesity epidemic. Archives of Internal Medicine 170 (18):1695-700. doi:10.1001/ archinternmed.2010.314.

Matoti-Mvalo, T., and T. B. Puoane. 2011. Perceptions of body size and its association with HIV/ AIDS. South African Journal of Clinical Nutrition 24 (1):40-45. doi:10.1080/ 16070658.2011 .11734348$.

Mchiza, Z. J., J. H. Goedecke, and E. V. Lambert. 2011. Intra-familial and ethnic effects on attitudinal and perceptual body image: A cohort of South African mother-daughter dyads. BMC Public Health 11:433. doi:10.1186/1471-2458-11-433.

Mchiza, Z. J., W. Parker, M. Makoae, R. Sewpaul, T. Kupamupindi, and D. Labadarios. 2015. Body image and weight control in South Africans 15 years or older: SANHANES-1. BMC Public Health 15 (1):992. doi:10.1186/s12889-015-2324-y. 
Mciza, Z, J. H. Goedecke, N. P. Steyn, K. Charlton, T. Puoane, S. Meltzer, N. S. Levitt, and E. V. Lambert. 2005. Development and validation of instruments measuring body image and body weight dissatisfaction in South African mothers and their daughters. Public Health Nutrition 8 (5):509-19. doi:10.1079/PHN2005814.

Mvo, Z, J. Dick, and K. Steyn. 1999. Perceptions of overweight African women about acceptable body size of women and children. Curationis 22 (2):27-31. doi:10.4102/curationis.v22i2.719.

NCD Risk Factor Collaboration (NCD-RisC). 2016. Trends in adult body-mass index in 200 countries from 1975 to 2014: A pooled analysis of 1698 population-based measurement studies with 19.2 million participants. Lancet 387(10026):1377-96. doi:10.1016/S0140-6736(16)30054-X.

NCD Risk Factor Collaboration (NCD-RisC) - Africa Working Group. 2017. Trends in obesity and diabetes across Africa from 1980 to 2014: An analysis of pooled population-based studies. International Journal of Epidemiology 46(5):1421-32. doi:10.1093/ije/dyx078.

Price, A. J., A. C. Crampin, A. Amberbir, N. Kayuni-Chihana, C. Musicha, T. Tafatatha, K. Branson, D. A. Lawlor, E. Mwaiyeghele, L. Nkhwazi, et al. 2018. Prevalence of obesity, hypertension, and diabetes, and cascade of care in sub-Saharan Africa: A cross-sectional, population-based study in rural and urban Malawi. The Lancet. Diabetes \& Endocrinology 6 (3):208-22. doi:10.1016/S22138587(17)30432-1.

Prioreschi, A., S. V. Wrottesley, E. Cohen, A. Reddy, R. Said-Mohamed, R. Twine, S. M. Tollman, K. Kahn, D. B. Dunger, and S. A. Norris. 2017. Examining the relationships between body image, eating attitudes, BMI, and physical activity in rural and urban South African young adult females using structural equation modeling. PloS One 12 (11):e0187508. doi:10.1371/journal. pone.0187508.

Puoane, T., J. M. Fourie, M. Shapiro, L. Rosling, N. C. Tshaka, and A. Oelefse. 2005. "Big is beautiful" - An exploration with urban black community health workers in a South African township. South African Journal of Clinical Nutrition 18 (1):6-15. doi:10.1080/ 16070658.2005 .11734033$.

Puoane, T., K. Steyn, D. Bradshaw, R. Laubscher, J. Fourie, V. Lambert, and N. Mbananga. 2002. Obesity in South Africa: The South African demographic and health survey. Obesity Research 10:1038-48. doi:10.1038/oby.2002.141.

Puoane, T., L. Tsolekile, and N. Steyn. 2010. Perceptions about body image and sizes among Black African girls living in Cape Town. Ethnicity of Disease 20:29-34.

Puoane, T. R., J. M. Fourie, L. Tsolekile, J. H. Nel, and N. J. Temple. 2013. What do Black South African adolescent girls think about their body size? Journal of Hunger of Environmental Nutrition 8 (1):85-94. doi:10.1080/19320248.2012.758067.

Sonneville, K. R., J. P. Calzo, N. J. Horton, J. Haines, S. B. Austin, and A. E. Field. 2012. Body satisfaction, weight gain and binge eating among overweight adolescent girls. International Journal of Obesity 36 (7):944-49. doi:10.1038/ijo.2012.68.

Tang, Z, C. Wang, X. Song, J. Shi, A. Mitnitski, X. Fang, P. Yu, and K. Rockwood. 2013. Cooccurrence of cardiometabolic diseases and frailty in older Chinese adults in the Beijing longitudinal study of ageing. Age and Ageing 42 (3):346-51. doi:10.1093/ageing/aft004.

van Zyl, S., L. J. van der Merwe, C. M. Walsh, A. J. Groenewald, and F. C. van Rooyen. 2012. Riskfactor profiles for chronic diseases of lifestyle and metabolic syndrome in an urban and rural setting in South Africa. African Journal of Primary Health Care of Family Medicine 4 (1):346. doi: 10.4102/phcfm.v4i1.346.

Williamson, D. A., D. H. Gleaves, P. C. Watkins, and D. G. Schlundt. 1993. Validation of self-ideal body size discrepancy as a measure of body dissatisfaction. Journal of Psychopathology and Behavioral Assessment 15 (1):57-68. doi:10.1007/BF00964324. 